\title{
Pediatric gastrointestinal endoscopy: European Society of Gastro- intestinal Endoscopy (ESGE) and European Society for Paediatric Gastroenterology Hepatology and Nutrition (ESPGHAN) Guideline Executive summary
}

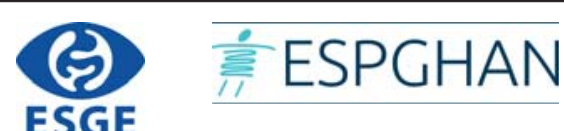

\section{Authors}

Andrea Tringali ${ }^{1,{ }^{*},}$, Mike Thomson 2, , Jean-Marc Dumonceau ${ }^{3}$, Marta Tavares $^{4}$, Merit M. Tabbers ${ }^{5}$, Raoul Furlano ${ }^{6}$, Manon Spaander ${ }^{7}$, Cesare Hassan ${ }^{8}$, Christos Tzvinikos ${ }^{9}$, Hanneke ljsselstijn ${ }^{10}$, Jérôme Viala ${ }^{11}$, Luigi Dall'Oglio' ${ }^{12}$, Marc Benninga ${ }^{5}$, Rok Orel ${ }^{13}$, Yvan Vandenplas ${ }^{4}$, Radan Keil ${ }^{15}$, Claudio Romano ${ }^{16}$, Eva Brownstone ${ }^{17}$, Štěpán Hlava ${ }^{15}$, Patrick Gerner ${ }^{18}$, Werner Dolak ${ }^{19}$, Rosario Landi ${ }^{1}$, Wolf Dietrich Huber ${ }^{19}$, Simon Everett ${ }^{20}$, Andreas Vecsei ${ }^{21}$, Lars Aabakken ${ }^{22}$, Jorge Amil-Dias ${ }^{4}$, Alessandro Zambelli ${ }^{23}$

\section{Institutions}

1 Digestive Endoscopy Unit, Catholic University, Rome, Italy

2 International Academy for Paediatric Endoscopy Training, Sheffield Children's Hospital, Weston Bank, Sheffield, UK

3 Gedyt Endoscopy Center, Buenos Aires, Argentina

4 Department of Pediatric Gastroenterology, Centro Hospitalar de São João, Porto, Portugal

5 Department of Pediatric Gastroenterology, Emma Children's Hospital, Academic Medical Center, Amsterdam, The Netherlands

6 Department of Pediatric Gastroenterology and Nutrition, University Children's Hospital Basel, Switzerland

7 Department of Gastroenterology, Erasmus MC Cancer Institute, Rotterdam, The Netherlands

8 Department of Gastroenterology, Nuovo Regina Margherita Hospital, Rome, Italy

9 Department of Pediatric Gastroenterology, Alder Hey Children's Hospital, Liverpool, UK

10 Department of Pediatric Surgery and Intensive Care, Erasmus MC, Sophia Children's Hospital, Rotterdam, The Netherlands

11 Department of Pediatric Gastroenterology, Robert-Debré Hospital, Paris, France

12 Digestive Endoscopy and Surgery Unit, Bambino Gesù Children's Hospital-IRCCS, Rome, Italy

13 Department of Gastroenterology, Hepatology and Nutrition, University Children's Hospital Ljubljana, Slovenia

14 Pediatric Gastroenterology, UZ Brussel, Vrije Universiteit Brussel, Brussels, Belgium

15 Department of Gastroenterology, Motol University Hospital, Prague, Czech Republic

16 Department of Pediatrics, University of Messina, Italy

17 IV Medical Department, Rudofstiftung Hospital, Vienna, Austria

18 Department of General Pediatrics, Children's Hospital Freiburg University, Freiburg, Germany
19 Division of Gastroenterology and Hepatology, Department of Internal Medicine III, Medical University of Vienna, Vienna, Austria

20 Department of Gastroenterology, Leeds Teaching Hospitals NHS Trust, Leeds, UK

21 Department for Pediatric Nephrology and Gastroenterology, Medical University of Vienna, Austria

22 GI Endoscopy Unit, OUS, Rikshospitalet University Hospital, Oslo, Norway

23 Gastroenterology and Digestive Endoscopy Unit, Ospedale Nuovo Robbiani di Soresina, Italy

Bibliography

DOI http://dx.doi.org/10.1055/s-0042-111002

Published online: 12.9.2016 | Endoscopy 2017; 49: 83-91

(๑) Georg Thieme Verlag KG Stuttgart · New York

ISSN 0013-726X

This Executive summary and the full Guideline are published simultaneously in Endoscopy and the Journal of Pediatric Gastroenterology and Nutrition, respectively. Copyright 2016 (c) Georg Thieme Verlag KG and (c) Wolters Kluwer.

\section{Corresponding author}

Andrea Tringali, MD PhD, Digestive Endoscopy Unit, Catholic University, Largo A. Gemelli 8, 00168 Rome, Italy,

Fax: +39-6-30157220

andrea.tringali@unicatt.it

\section{ABSTRACT}

This Executive summary of the Guideline on pediatric gastrointestinal endoscopy from the European Society of Gastrointestinal Endoscopy (ESGE) and the European Society for Paediatric Gastroenterology Hepatology and Nutrition (ESPGHAN) refers to infants, children, and adolescents aged $0-18$ years. The areas covered include: indications for diagnostic and therapeutic esophagogastroduodenoscopy and ileocolonoscopy; endoscopy for foreign body ingestion; endoscopic management of corrosive ingestion and stricture/stenosis; upper and lower gastrointestinal bleeding; endoscopic retrograde cholangiopancreatography, and endoscopic ultrasonography. Percutaneous endoscopic gastrostomy and endoscopy specific to inflammatory bowel disease (IBD) have been dealt with in other Guidelines and are therefore not mentioned in this Guideline. Training and ongoing skill maintenance will be addressed in an imminent sister publication.

\footnotetext{
* Co-First authors
} 


\begin{tabular}{|c|c|}
\hline \multicolumn{2}{|c|}{ ABBREVIATIONS } \\
\hline AUGIB & acute upper gastrointestinal bleeding \\
\hline CT & computed tomography \\
\hline EGD & esophagogastroduodenoscopy \\
\hline ERCP & $\begin{array}{l}\text { endoscopic retrograde cholangiopancreato- } \\
\text { graphy }\end{array}$ \\
\hline ESGE & European Society of Gastrointestinal Endoscopy \\
\hline ESPGHAN & European Society for Paediatric Gastroenterology \\
\hline & Hepatology and Nutrition \\
\hline EBUS & endobronchial ultrasound \\
\hline EUS & endoscopic ultrasonography \\
\hline FCSEMS & fully covered self-expandable metal stent \\
\hline Gl & gastrointestinal \\
\hline GRADE & $\begin{array}{l}\text { Grading of Recommendations Assessment, } \\
\text { Development and Evaluation }\end{array}$ \\
\hline GVHD & graft-versus-host disease \\
\hline IBD & inflammatory bowel disease \\
\hline MMC & mitomycin C \\
\hline NSAID & non-steroidal anti-inflammatory drug \\
\hline RCT & randomized controlled trial \\
\hline TAC & triamcinolone acetonide \\
\hline
\end{tabular}

\section{Time definitions}

Emergent/emergency $<2$ hours

Urgent/urgently $<12$ hours or $<24$ hours and defined in text Early $<48$ hours but may be at clinician's discretion

\section{Introduction}

Gastrointestinal (GI) endoscopy in the pediatric population has evolved during the last 30 years with an increasing number of diagnostic and therapeutic applications. Technological improvements in endoscope design and endoscopic devices have contributed to the evolution of pediatric endoscopy.

Endoscopy in the pediatric population has generally, to date, been performed by both non-pediatric endoscopists in conjunction with pediatricians and by pediatric endoscopists in specialized centers.

This document is the Executive summary of the Guideline on pediatric GI endoscopy [1] commissioned by the European Society for Paediatric Gastroenterology Hepatology and Nutrition (ESPGHAN) and the European Society of Gastrointestinal Endoscopy (ESGE). The aims of the evidence-based and consensus-based Guideline are to provide a comprehensive review of the clinical indications and timing of diagnostic and therapeutic endoscopy in pediatric patients. It is not meant to be a comprehensive overview of a patient's care, and investigation/therapy for each area will, of course, involve the clinician's discretion regarding the place of endoscopy in overall management, encompassing, as it must, complementary non-endoscopic approaches. The role of endoscopy in the overall management will depend on a number of factors, including but not limited to the specific clinical features, the availability/appropriateness of non-endoscopic approaches, and the available skills of the endoscopist. This Guideline tries to address this issue of endoscopist skills, and certainly the upcoming ESPGHAN/ESGE Guideline on training in pediatric endoscopy will help in this respect. How, where, and when endoscopy may be employed in pediatric management is particularly important in the areas of $\mathrm{Gl}$ bleeding and endoscopic retrograde cholangiopancreatography/endoscopic ultrasound (ERCP/EUS).

This undertaking is the first joint endoscopy review between pediatric and adult endoscopy representative groups in Europe. Our aspiration is that this Guideline may lead to a degree of standardization in the utility and practice of endoscopic approaches for children, thereby contributing to excellence and appropriateness of care.

Percutaneous endoscopic gastrostomy and endoscopy specific to inflammatory bowel disease (IBD) have been dealt with in other Guidelines [2-4], and are therefore not mentioned in the pediatric Gl endoscopy Guideline. Training and ongoing skill maintenance will be addressed in an imminent sister publication.

\section{Methods}

ESGE and ESPGHAN agreed to develop a joint guideline. Two guideline leaders (A.T. for ESGE and M.T. for ESPGHAN) invited the listed authors to participate in the project. The key questions were prepared by the coordinating team (A.T., M.T., M. M.T., R.F., Y.V., J.-M.D.) and then approved by the other members. The coordinating team established task force subgroups, each with its own leader, and assigned the following key topics among the task forces: esophagogastroduodenoscopy (EGD) and ileocolonoscopy; foreign bodies; corrosive ingestion; corrosive ingestion and esophageal strictures/stenoses; GI bleeding; endoscopic retrograde cholangiopancreatography (ERCP); and endoscopic ultrasonography (EUS). Each task force performed a systematic literature search to prepare evidencebased and well-balanced statements on their assigned key questions. Searches were performed in PubMed and/or EMBASE and/or Cochrane (publication date from 2000 to May 2015, or before if strictly needed), including as a minimum the key words "pediatric" and "endoscopy." All articles studying the application of diagnostic and therapeutic endoscopy in the pediatric age range were selected by title or abstract. The results of the relevant publications were summarized in literature tables and graded by the level of evidence and strength of recommendation according to the Grading of Recommendations Assessment, Development and Evaluation (GRADE) system $[5,6]$. Each task force proposed statements on their assigned key questions which were discussed and voted on during the plenary meeting held in February 2015 in Munich. In November 2015, a draft prepared by A.T., C.H. and M.T. was sent to all group members. After agreement from all the authors on a final version, the manuscript was reviewed by two members of the ESGE Governing Board, ESGE individual members and the ESPGHAN Council.

The manuscript was then submitted to the Journal of Pediatric Gastroenterology and Nutrition for publication in full length and to Endoscopy for publication of the Executive summary. 
Both the Guideline and Executive summary were issued in 2016 and will be considered for review and update in 2021 or sooner if new and relevant evidence becomes available. Any updates to the Guideline or Executive summary in the interim will be noted on the ESGE and ESPGHAN websites: http://www. esge.com/esge-guidelines.html and http://www.espghan.org/ guidelines/

\section{Recommendations}

\section{Esophagogastroduodenoscopy (EGD)}

ESGE/ESPGHAN suggest diagnostic and therapeutic EGD for the indications listed in $>$ Table 1 and $>$ Table 2 , respectively. (Weak recommendation, low quality evidence.)

ESGE/ESPGHAN do not suggest EGD in the case of uncomplicated gastroesophageal reflux, functional gastrointestinal disorders, or for diagnosing perforation. (Weak recommendation, low quality evidence.)

ESGE/ESPGHAN suggest routine tissue sampling even in the absence of visible endoscopic abnormalities in all children undergoing EGD. (Weak recommendation, low quality evidence.)

ESGE/ESPGHAN suggest using ESPGHAN guidelines (on eosinophilic esophagitis, Helicobacter pylori, celiac disease, and inflammatory bowel disease [IBD]) for precise indications and preferred sites for biopsy during EGD in children suspected of a specific disease ( $\downarrow$ Table 3 ). (Weak recommendation, low quality evidence.)

ESGE/ESPGHAN suggest performing EGD in children under general anesthesia or, only if general anesthesia is not available, under deep sedation in a carefully monitored environment. (Weak recommendation, low quality evidence.)

ESGE/ESPGHAN suggest performing EGD in a child-friendly setting with appropriate equipment and by an endoscopist trained in pediatric gastroenterology. (Weak recommendation, low quality evidence.)

ESGE/ESPGHAN suggest that when adult endoscopists perform pediatric procedures, collaboration between adult gastroenterologists and pediatricians is always warranted. (Weak recommendation, low quality evidence.)

ESGE/ESPGHAN suggest that the choice of gastroscope type should depend on the child's weight and age ( $\triangleright$ Table 4). (Weak recommendation, low quality evidence.)

\section{Ileocolonoscopy}

ESGE/ESPGHAN suggest ileocolonoscopy for the diagnostic and therapeutic indications listed in $>$ Table 5. (Weak recommendation, low quality evidence.)

ESGE/ESPGHAN suggest against ileocolonoscopy in the case of toxic megacolon, recent colonic perforation (<28 days), recent intestinal resection ( $<7$ days), or functional $\mathrm{Gl}$ disorders. (Weak recommendation, low quality evidence.)

ESGE/ESPGHAN suggest performing ileocolonoscopy in children under general anesthesia or, only if general anesthesia is not available, under deep sedation in a carefully monitored environment. (Weak recommendation, low quality evidence.)

ESGE/ESPGHAN suggest that ileocolonoscopy should be performed in a child-friendly setting with appropriate equip-
- Table 1 Typical diagnostic and therapeutic indications, non-indications, and contraindications for esophagogastroduodenoscopy (EGD) in pediatric patients.

\begin{tabular}{|c|c|}
\hline \multirow[t]{11}{*}{ Diagnostic indications } & Weight loss, failure to thrive \\
\hline & Unexplained anemia \\
\hline & $\begin{array}{l}\text { Abdominal pain with suspicion of an } \\
\text { organic disease }\end{array}$ \\
\hline & Dysphagia or odynophagia \\
\hline & Caustic ingestion \\
\hline & $\begin{array}{l}\text { Recurrent vomiting with unknown } \\
\text { cause }\end{array}$ \\
\hline & Hematemesis \\
\hline & Hematochezia \\
\hline & Unexplained chronic diarrhea \\
\hline & Suspicion of graft versus host disease \\
\hline & $\begin{array}{l}\text { Chronic GERD, to exclude other dis- } \\
\text { eases, or surveillance of Barrett's } \\
\text { esophagus }\end{array}$ \\
\hline \multirow[t]{11}{*}{ Therapeutic indications } & $\begin{array}{l}\text { Percutaneous endoscopic gastrostomy } \\
\text { (re)placement }\end{array}$ \\
\hline & Duodenal tube placement \\
\hline & Foreign body removal \\
\hline & Food impaction \\
\hline & Hemostasis \\
\hline & Percutaneous jejunostomy placement \\
\hline & Esophageal varices \\
\hline & $\begin{array}{l}\text { Dilation of esophageal or upper GI } \\
\text { strictures }\end{array}$ \\
\hline & Perforation \\
\hline & Achalasia \\
\hline & Polypectomy \\
\hline \multirow[t]{2}{*}{ Non-indications } & Uncomplicated GERD \\
\hline & Functional GI disorders \\
\hline Contraindications & To diagnose perforation \\
\hline
\end{tabular}

ment and by an endoscopist trained in pediatric gastroenterology. (Weak recommendation, low quality evidence.)

ESGE/ESPGHAN suggest that when non-pediatric endoscopists perform pediatric procedures in older children, collaboration with a pediatrician is always warranted. (Weak recommendation, low quality evidence.)

ESGE/ESPGHAN suggest that the choice of colonoscope type should depend on the child's weight and age ( $\triangleright$ Table 4). (Weak recommendation, low quality evidence.) 
-Table2 Diagnostic indications for esophagogastroduodenoscopy (EGD) in pediatric patients: symptoms/signs according to suspected disease.

\begin{tabular}{|l|l|}
\hline Symptoms/signs & Suspicion of: \\
\hline $\begin{array}{l}\text { Weight loss, failure to thrive, } \\
\text { chronic diarrhea, malabsorption, } \\
\text { anemia, abdominal pain with } \\
\text { suspicion of an organic disease }\end{array}$ & $\begin{array}{l}\text { Celiac disease or IBD, giardiasis, } \\
\text { allergic enterocolitis, bleeding } \\
\text { lesions, graft versus host disease }\end{array}$ \\
\hline $\begin{array}{l}\text { Dysphagia, odynophagia, chest } \\
\text { pain, feeding difficulty }\end{array}$ & $\begin{array}{l}\text { Foreign body ingestion, food } \\
\text { impaction, caustic ingestion or } \\
\text { eosinophilic esophagitis }\end{array}$ \\
\hline $\begin{array}{l}\text { Hematemesis, hematochezia, } \\
\text { melena }\end{array}$ & $\begin{array}{l}\text { Polyps, angiodysplasia, arterio- } \\
\text { venous malformations, peptic ul- } \\
\text { cer with or without Helicobacter } \\
\text { pylori infection, less common } \\
\text { conditions such as duplication } \\
\text { cysts }\end{array}$ \\
\hline Family history of polyposis & $\begin{array}{l}\text { Polyps (diagnostic and } \\
\text { surveillance) }\end{array}$ \\
\hline IBD, inflammatory bowel disease. & \\
\hline
\end{tabular}

- Table 3 Indication and site for tissue sampling during upper and lower endoscopy in pediatric patients.

\begin{tabular}{|l|l|}
\hline Indication & Tissue samples: sites and numbers \\
\hline $\begin{array}{l}\text { Eosinophilic } \\
\text { esophagitis }\end{array}$ & $\begin{array}{l}\text { At least } 3 \text { biopsies should be taken, one from } \\
\text { proximal mid and distal esophagus, regardless } \\
\text { of the endoscopic appearance of the esopha- } \\
\text { gus }\end{array}$ \\
\hline $\begin{array}{l}\text { Helicobacter pylori } \\
\text { infection }\end{array}$ & $\begin{array}{l}2 \text { biopsies from both the antrum and the } \\
\text { corpus ( } \pm \text { fundus) }\end{array}$ \\
\hline Celiac disease & $\begin{array}{l}\text { At least } 1 \text { biopsy from the duodenal bulb and } \\
\text { at least } 4 \text { biopsies from the second or third } \\
\text { portion of the duodenum }\end{array}$ \\
\hline IBD & $\begin{array}{l}\text { Multiple biopsies (2 or more per section) from } \\
\text { all sections of the visualized GI tract, even in } \\
\text { the absence of macroscopic lesions }\end{array}$ \\
\hline IBD, inflammatory bowel disease; GI, gastrointestinal.
\end{tabular}

\section{Bowel preparation for ileocolonoscopy in children}

ESGE/ESPGHAN recommend low-volume preparation for bowel cleansing in children, using either polyethylene glycol plus ascorbate or picosulphate plus magnesium citrate/Senokot. (Strong recommendation, high quality evidence.)

ESGE/ESPGHAN recommend against the use of sodium phosphate for bowel cleansing. (Strong recommendation, high quality evidence.)

\section{Ileocolonoscopy in children: biopsy, carbon dioxide} insufflation, ileal intubation, polypectomy technique

ESGE/ESPGHAN suggest routine biopsy even in the absence of visible endoscopic abnormalities in all children with suspected IBD undergoing ileocolonoscopy. (Weak recommendation, low quality evidence.)

ESGE/ESPGHAN suggest using ESPGHAN guidelines relating to ulcerative colitis and the revised Porto criteria for diagnosis of IBD for precise indications and preferred sites to biopsy. (Weak recommendation, low quality evidence.)

ESGE/ESPGHAN did not find any evidence to recommend against or for the use of routine carbon dioxide insufflation during ileocolonoscopy in children. Pain seems to be rare and mild after ileocolonoscopy in children. (Weak recommendation, low quality evidence.)

ESGE/ESPGHAN suggest that ileal intubation should be attempted in symptomatic children with abdominal pain, intestinal bleeding, diarrhea, or with any suspicion of IBD. (Weak recommendation, low quality evidence.)

ESGE/ESPGHAN suggest removal of very small polyps ( $<3 \mathrm{~mm}$ ) by cold biopsy forceps and $3-8 \mathrm{~mm}$ polyps by hot or cold snaring. Cold snaring is advisable in the right colon where the perforation risk is higher. For polyps $>8 \mathrm{~mm}$, hot snaring is suggested. (Weak recommendation, low quality evidence.)

\section{Foreign body ingestion}

ESGE/ESPGHAN recommend an early referral to the emergency room and $\mathrm{X}$-ray evaluation in all patients with suspected foreign body ingestion even if asymptomatic. Biplane radiographs should be obtained of the neck, chest, abdomen, and pelvis if

Table 4 Types of endoscopes used in pediatric patients according to body weight, age, and procedure.

\begin{tabular}{|c|c|c|c|c|}
\hline & EGD & Colonoscopy & ERCP & EUS \\
\hline \multicolumn{5}{|l|}{ Weight or age } \\
\hline$<10 \mathrm{~kg}$ or $<1$ year & $\begin{array}{l}\leq 6 \mathrm{~mm} \text { gastroscope } \\
\text { preferred. } \\
\text { Consider standard adult } \\
\text { gastroscope if endotherapy } \\
\text { required. }\end{array}$ & $\begin{array}{l}\leq 6 \mathrm{~mm} \text { gastroscope, stand- } \\
\text { ard adult gastroscope, or } \\
\text { pediatric colonoscope. }\end{array}$ & $7.5 \mathrm{~mm}$ duodenoscope & $\begin{array}{l}\text { Miniprobe or } 7.4 \mathrm{~mm} \\
\text { EBUS scope. }\end{array}$ \\
\hline$\geq 10 \mathrm{~kg}$ or $\geq 1$ year & $\begin{array}{l}\text { Standard adult gastroscope. } \\
\text { Therapeutic gastroscope if } \\
\text { needed. }\end{array}$ & $\begin{array}{l}\text { Pediatric or adult } \\
\text { colonoscope. }\end{array}$ & $\begin{array}{l}\text { Therapeutic duodenoscope } \\
\text { ( } 4.2 \mathrm{~mm} \text { operative channel) }\end{array}$ & $\begin{array}{l}\text { Miniprobe or } 7.4 \mathrm{~mm} \\
\text { EBUS scope. }\end{array}$ \\
\hline$\geq 15 \mathrm{~kg}$ or $\geq 3$ years & - & - & - & $\begin{array}{l}\text { Adult radial/linear } \\
\text { echoendoscope }\end{array}$ \\
\hline
\end{tabular}


- Table 5 Typical diagnostic and therapeutic indications, non-indications, and contraindications for ileocolonoscopy in pediatric patients.

\begin{tabular}{|l|l|}
\hline Diagnostic indications & Unexplained anemia \\
\hline & Unexplained chronic diarrea \\
\hline & Perianal lesions (fistula, abscess) \\
\hline & Rectal blood loss \\
\hline & Unexplained failure to thrive \\
\hline Suspicion of graft versus host \\
\hline & disease \\
\hline Rejection or complications after \\
\hline intestinal transplantation
\end{tabular}

indicated. Computed tomography (CT) scan can be considered for radiolucent foreign bodies. (Strong recommendation, moderate quality evidence.)

ESGE/ESPGHAN suggest early EGD if the foreign body is in the esophagus. (Weak recommendation, low quality evidence.)

\section{Blunt foreign bodies and coins}

ESGE/ESPGHAN recommend removal of blunt foreign bodies and coins or impacted food from the esophagus urgently $(<24$ hours), even in asymptomatic children. If the child is symptomatic an emergent ( $<2$ hours) removal is indicated especially for button batteries. (Strong recommendation, moderate quality evidence.)

ESGE/ESPGHAN suggest removal of blunt foreign bodies from the stomach or duodenum if the child is symptomatic or if the object is wider than $2.5 \mathrm{~cm}$ in diameter or $>6 \mathrm{~cm}$ in length. Otherwise, blunt foreign bodies in the stomach can be followed and retrieved only if they produce symptoms or do not pass spontaneously after 4 weeks. (Weak recommendation, low quality evidence.)

\section{Sharp-pointed objects}

ESGE/ESPGHAN recommend emergent ( $<2$ hours) removal of sharp-pointed objects located in the esophagus (all cases). (Strong recommendation, moderate quality evidence.)

ESGE/ESPGHAN recommend emergent ( $<2$ hours) removal of sharp-pointed objects in the stomach or proximal duodenum even in asymptomatic children. (Strong recommendation, moderate quality evidence.)

\section{Batteries}

ESGE/ESPGHAN recommend to emergently (<2 hours) remove button batteries impacted in the esophagus. (Strong recommendation, low quality evidence.)

ESGE/ESPGHAN suggest to remove button batteries in the stomach emergently ( $<2$ hours) if the child is symptomatic and/or has a known or suspected anatomical pathology in the GI tract (e.g. Meckel's diverticulum), and/or has simultaneously swallowed a magnet. (Weak recommendation, low quality evidence.)

ESGE/ESPGHAN suggest that button batteries larger than $>20 \mathrm{~mm}$ present in the stomach should be checked by radiography and removed if still in place after more than 48 hours. (Weak recommendation, low quality evidence.)

ESGE/ESPGHAN recommend an urgent endoscopic removal (< 24 hours) for single cylindrical battery ingestion when impacted in the esophagus and as soon as possible elsewhere in the $\mathrm{Gl}$ tract when the child is symptomatic. (Strong recommendation, moderate quality evidence.)

ESGE/ESPGHAN suggest that a single cylindrical battery in the stomach can be observed and the child monitored as an outpatient and followed by X-ray 7-14 days after ingestion if the battery is not passed in the stool. (Weak recommendation, low quality evidence.)

\section{Magnets}

ESGE/ESPGHAN recommend urgent (<24 hours) removal of all magnets within endoscopic reach. For those beyond endoscopic reach, close observation and surgical consultation for non-progression through the Gl tract is advised. (Strong recommendation, moderate quality evidence.)

\section{Food bolus impaction}

ESGE/ESPGHAN recommend removal of impacted food from the esophagus as an emergency 2 hours from the time of presentation (and ideally from the time of ingestion) in case of symptoms (drooling, neck pain). If the child is asymptomatic an urgent (< 24 hours) removal is indicated. (Strong recommendation, moderate quality evidence.)

ESGE/ESPGHAN suggest investigation for underlying pathology of the esophagus in all cases of food impaction. (Weak recommendation, low quality evidence.) 
Drug packets

ESGE/ESPGHAN recommend against endoscopic removal of drug-containing packets. (Strong recommendation, low quality evidence.)

\section{Equipment for removal of foreign bodies}

ESGE/ESPGHAN suggest that flexible endoscopy is an effective and safe procedure for removing foreign bodies from the $\mathrm{GI}$ tract, with a high success rate using retrieval nets, polypectomy snares, and rat-tooth forceps. (Weak recommendation, very low quality evidence.)

\section{Corrosive ingestion}

ESGE/ESPGHAN suggest that every child that has ingested a corrosive substance should have a thorough follow-up, with endoscopy dictated only by symptoms, and dependent on the symptoms the timing should be within 24 hours. (Strong recommendation, high quality evidence.)

ESGE/ESPGHAN recommend that every child with a suspected caustic ingestion and symptoms/signs (any oral lesions, vomiting, drooling, dysphagia, hematemesis, dyspnea, abdominal pain, etc) should have an EGD in order to identify all consequent digestive tract lesions. (Strong recommendation, high quality evidence.)

ESGE/ESPGHAN suggest that in the case of suspected corrosive ingestion EGD is withheld if the child is asymptomatic (no drooling of saliva/other symptoms and no mouth lesions) and that adequate follow-up is assured. (Weak recommendation, moderate quality evidence.)

ESGE/ESPGHAN recommend to have the same grade of suspicion for both acidic and alkali ingestion regarding potential mucosal injury. (Alkali ingestion, especially lye, is associated with more severe esophageal lesions and severe gastric lesions can occur in acidic ingestion.) Stricture development has been associated with both acidic and alkali ingestion. (Strong recommendation, high quality evidence.)

ESGE/ESPGHAN recommend high doses of intravenous dexamethasone $\left(1 \mathrm{~g} / 1.73 \mathrm{~m}^{2}\right.$ per day) administration for a short period ( 3 days) in Ilb esophagitis after corrosive ingestion as a method of preventing the development of esophageal stricture. There is no evidence of benefit for the use of corticosteroids in other grades of esophagitis (I, Ila, III). (Strong recommendation, moderate quality evidence.)

\section{Benign esophageal strictures}

ESGE/ESPGHAN recommend esophageal dilation using balloon or bougies for benign esophageal strictures only when symptoms occur. (Strong recommendation, low quality evidence.)

ESGE/ESPGHAN suggest the following definition of a benign refractory or recurrent stricture in children: "An anatomic restriction because of cicatricial luminal compromise or fibrosis that results in dysphagia in the absence of endoscopic evidence of inflammation. This may occur as the result of either an inability to successfully remediate the anatomic problem to obtain age-appropriate feeding possibilities after a maximum of 5 dilation sessions (refractory) with maximal 4-week intervals, or as a result of an inability to maintain a satisfactory luminal diameter for 4 weeks once the age-appropriate feeding diameter has been achieved (recurrent)." (Weak recommendation, very low level of evidence.)

ESGE/ESPGHAN suggest temporary stent placement or application of topical mitomycin C (MMC) following dilation for refractory esophageal stenosis in children. ESGE/ESPGHAN do not suggest the routine use of intralesional steroids for refractory esophageal stenosis in children. (Weak recommendation, low quality evidence.)

In patients operated for esophageal atresia, ESGE/ESPGHAN suggest long-term endoscopic surveillance for Barrett's esophagus and cancer. Frequency would be dictated by the presence or not of dysplasia and should follow standard guidelines already published in the literature. (Weak recommendation, low quality evidence.)

\section{Upper and lower GI bleeding}

ESGE/ESPGHAN suggest that, having employed all necessary medical interventions as standard, EGD be performed very early ( $\leq 12 \mathrm{~h}$ ) in acute upper Gl bleeding (AUGIB) cases which require ongoing circulatory support or where a large hematemesis or melena occurs. (Weak recommendation, low quality evidence.)

ESGE/ESPGHAN recommend that, having employed all necessary medical interventions as standard, EGD be performed very early $(<12 \mathrm{~h})$ in AUGIB in cases with known esophageal varices. (Strong recommendation, moderate quality evidence.)

ESGE/ESPGHAN suggest that, having employed all necessary medical interventions as standard, EGD be performed within 24 hours in AUGIB cases which require transfusion due to hemoglobin drop below $8 \mathrm{~g} / \mathrm{dL}$, where an acute drop of $2 \mathrm{~g} /$ $\mathrm{dL}$ is identified, and in those who are stable but whose bleeding score is above a recognized threshold/validated score for probable endoscopic intervention requirement. (Weak recommendation, moderate quality evidence.)

ESGE/ESPGHAN suggest that EGD be performed before hospital discharge in children with AUGIB and pre-existing liver disease or portal hypertension. (Weak recommendation, low quality evidence.)

ESGE/ESPGHAN do not suggest routine use of wireless capsule endoscopy/enteroscopy in AUGIB in children. (Weak recommendation, moderate quality evidence.)

ESGE/ESPGHAN suggest that urgent (24 hours) therapeutic ileocolonoscopy is not usually necessary in lower GI bleeding unless severe enough to cause circulatory compromise but diagnostic ileocolonoscopy is needed as soon as is practical and safe. (Weak recommendation, weak quality evidence.)

\section{Endoscopic hemostasis technique for GI bleeding in children}

ESGE/ESPGHAN recommend hemostasis of esophageal variceal bleeding in children, using band ligation, if feasible, or sclerotherapy as an alternative. (Strong recommendation, moderate quality evidence.)

ESGE/ESPGHAN suggest that the treatment of peptic ulcers and Dieulafoy's lesion should not be carried out with epinephrine injection alone but in combination with thermal or me- 
- Table 6 Typical indications for ERCP in pediatric patients.

\begin{tabular}{|l|l|l|l|}
\hline \multicolumn{1}{|l|}{$\begin{array}{l}\text { Biliary } \\
\text { Diagnostic }\end{array}$} & Therapeutic & $\begin{array}{l}\text { Pancreatic } \\
\text { Diagnostic }\end{array}$ & Therapeutic \\
\hline Cholestasis in neonates and infants & Common bile duct stones & $\begin{array}{l}\text { Evaluation of anomalous biliopan- } \\
\text { creatic junction }\end{array}$ & Chronic pancreatitis \\
\hline Choledochal cyst & $\begin{array}{l}\text { Bile leak } \\
\text { (post-surgical/post-traumatic) }\end{array}$ & Pancreas divisum \\
\hline $\begin{array}{l}\text { Primary sclerosing cholangitis } \\
\text { (brush cytology) }\end{array}$ & Benign biliary strictures & $\begin{array}{c}\text { Pancreatic duct leak } \\
\text { (post-surgical/post-traumatic) }\end{array}$ \\
\hline & Primary sclerosing cholangitis & & Pancreatic pseudocyst \\
\hline ERCP, endoscopic retrograde cholangiopancreatography & Malignant biliary strictures & \\
\hline
\end{tabular}

chanical techniques. (Weak recommendation, low quality evidence.)

ESGE/ESPGHAN suggest adopting general anesthesia in children undergoing endoscopy for GI bleeding. General anesthesia is recommended in the case of variceal bleeding. Deep sedation may be used in less severe bleeding in older children. (Weak recomendation, low quality evidence.)

ESGE/ESPGHAN suggest using video capsule endoscopy (VCE) in children in the case of suspected small-intestinal bleeding and in addition balloon enteroscopy for therapeutic purposes. (Weak recommendation, moderate quality evidence.)

\section{Endoscopic retrograde cholangiopancreatography (ERCP)}

ESGE/ESPGHAN suggest ERCP in pediatric patients ( $>1$-yearold) for therapeutic purposes following diagnostic information from non-invasive diagnostic modalities such as magnetic resonance cholangiopancreatography (MRCP). Diagnostic ERCP can be considered in selected cases where advanced non-invasive imaging is inconclusive. (Weak recommendation, low quality evidence.)

ESGE/ESPGHAN recommend that therapeutic ERCP in pediatric patients (>1-year-old) is considered for diseases listed in - Table 6 following diagnostic information from non-invasive modalities such as MRCP. Results and complication rates of ERCP in children are similar to those reported in adults. (Weak recommendation, low quality evidence.)

ESGE/ESPGHAN suggest that diagnostic ERCP in neonates and infants ( $\leq 1$-year-old) with cholestatic hepatobiliary disease is considered if non-invasive investigations are not conclusive in order to allow timely referral to surgery for suspected biliary atresia or to avoid unnecessary surgery if biliary atresia is excluded. (Weak recommendation, low quality evidence.)

ESGE/ESPGHAN recommend that ERCP in children is performed by an experienced endoscopist, in a high-volume ter- tiary care center, and with pediatric involvement. (Strong recommendation, moderate quality evidence.)

ESGE/ESPGHAN suggest general anesthesia for ERCP in children. Deep/conscious sedation can be considered for teenagers (age 12-17 years) although general anesthesia is the preferred choice. (Weak recommendation, low quality evidence.)

Prophylaxis of post-ERCP pancreatitis with non-steroidal anti-inflammatory drugs (NSAIDs) (diclofenac/indomethacin suppository) is recommended in children older than 14 years. (Strong recommendation, high quality evidence.)

Protection of radiosensitive organs (thyroid gland, breasts, gonads and eyes) is recommended together with adjustment of collimation to the smaller size of children. (Strong recommendation, high quality evidence.)

ESGE/ESPGHAN recommend the pediatric 7.5-mm duodenoscope for children weighing $<10 \mathrm{~kg}$ and that a therapeutic duodenoscope can be used in those weighing $\geq 10 \mathrm{~kg}$. (Strong recommendation, low quality evidence.)

- Table 7 Typical indications for endoscopic ultrasonography in pediatric patients.

\begin{tabular}{|l|l|l|l|}
\hline Esophagus & Stomach & Duodenum & Biliopancreatic \\
\hline $\begin{array}{l}\text { Congenital } \\
\text { esophageal } \\
\text { stenosis }\end{array}$ & $\begin{array}{l}\text { Gastric } \\
\text { duplication }\end{array}$ & $\begin{array}{l}\text { Duodenal } \\
\text { duplication }\end{array}$ & Bile duct stones \\
\hline $\begin{array}{l}\text { Eosinophilic } \\
\text { esophagitis }\end{array}$ & $\begin{array}{l}\text { Gastric } \\
\text { varices }\end{array}$ & & $\begin{array}{l}\text { Pancreatic } \\
\text { pseudocyst } \\
\text { (diagnosis and } \\
\text { treatment) }\end{array}$ \\
\hline $\begin{array}{l}\text { Esophageal } \\
\text { duplications }\end{array}$ & & $\begin{array}{l}\text { Pancreatic } \\
\text { diseases (士FNA) }\end{array}$ \\
\hline FNA, fine-needle aspiration. & & \\
\hline
\end{tabular}




\section{Endoscopic ultrasonography (EUS)}

The endobronchial ultrasound (EBUS) endoscope can be adapted for EUS in children with a weight below $15 \mathrm{~kg}$. A standard linear echoendoscope should only be employed in children under general anesthesia, considering the stiff and potentially traumatic distal part. (Weak recommendation, low quality evidence.)

ESGE/ESPGHAN suggest the use of EUS in children only in tertiary referral centers with experience in therapeutic endoscopy. Strict collaboration between adult and pediatric gastroenterologists is required in the case of EUS with standard echoendoscopes. (Weak recommendation, low quality evidence.)

ESGE/ESPGHAN suggest the use of radial EUS with miniprobes to diagnose congenital esophageal strictures (tracheobronchial remnants vs. fibromuscular stenosis subtypes). (Weak recommendation, very low quality evidence.)

ESGE/ESPGHAN suggest consideration of EUS for the diagnosis of pancreaticobiliary diseases in children where non-invasive imaging modalities (ultrasonography, MRCP) are inconclusive ( $\triangleright$ Table 7$)$. (Weak recommendation, very low quality evidence.)

ESGE/ESPGHAN suggest that EUS-guided drainage of pancreatic pseudocysts in children should be performed in large EUS centers with specific experience and expertise. (Weak recommendation, low quality evidence.)

ESGE and ESPGHAN guidelines represent a consensus of best practice based on the available evidence at the time of preparation. They may not apply in all situations and should be interpreted in the light of specific clinical situations and resource availability. Further controlled clinical studies may be needed to clarify aspects of these statements, and revision may be necessary as new data appear. Clinical considerations may justify a course of action at variance to these recommendations. ESGE and ESPGHAN guidelines are intended to be an educational device to provide information that may assist endoscopists in providing care to patients. They are not rules and should not be construed as establishing a legal standard of care or as encouraging, advocating, requiring, or discouraging any particular treatment.

\section{Competing interests}

M.Th. has participated as a clinical investigator and/or advisory board member and/or consultant and/or speaker and/or for Danone/Nutricia, Nestlé, Mead Johnson, Movetis, Jannsen, Norgine, Reckitt-Benkeiser, Cook, Olympus_KeyMed, Fujinon, Storz, Pentax and Boston-Scientific.

A.T. has participated as a clinical investigator and/or advisory board member and/or consultant and/or speaker for Boston Scientific.

J-M. D. has not participated as a clinical investigator and/or advisory board member and/or consultant and/or speaker for any company.
M. Tav. has not participated as a clinical investigator and/or advisory board member and/or consultant and/or speaker for any company.

M. Tab. has not participated as a clinical investigator and/or advisory board member and/or consultant and/or speaker for any company.

R.F. has not participated as a clinical investigator and/or advisory board member and/or consultant and/or speaker for any company.

M.S. has not participated as a clinical investigator and/or advisory board member and/or consultant and/or speaker for any company.

C.H. has not participated as a clinical investigator and/or advisory board member and/or consultant and/or speaker for any company.

C.T. has not participated as a clinical investigator and/or advisory board member and/or consultant and/or speaker for any company.

H.I. has not participated as a clinical investigator and/or advisory board member and/or consultant and/or speaker for any company.

J.V. has not participated as a clinical investigator and/or advisory board member and/or consultant and/or speaker for any company.

L.D. has not participated as a clinical investigator and/or advisory board member and/or consultant and/or speaker for any company.

M.B. has participated as a clinical investigator and/or advisory board member and/or consultant and/or speaker for Shire, Movetis, Sucampo, Norgine, Astra Zeneca, Zeria, Novolac, Sensus, Danone/Nutricia and Friesland Campina.R.O. has not participated as a clinical investigator and/or advisory board member and/or consultant and/or speaker for any company.

R.K. has not participated as a clinical investigator and/or advisory board member and/or consultant and/or speaker for any company.

C.R. has not participated as a clinical investigator and/or advisory board member and/or consultant and/or speaker for any company.

E.B. has not participated as a clinical investigator and/or advisory board member and/or consultant and/or speaker for any company.

S.H. has not participated as a clinical investigator and/or advisory board member and/or consultant and/or speaker for any company.

W.D. has not participated as a clinical investigator and/or advisory board member and/or consultant and/or speaker for any company.

W-D.H. has not participated as a clinical investigator and/or advisory board member and/or consultant and/or speaker for any company.

S.E. has participated as a clinical investigator and/or advisory board member and/or consultant and/or speaker for Olympus.

A.V. has not participated as a clinical investigator and/or advisory board member and/or consultant and/or speaker for any company. 
L.A. has not participated as a clinical investigator and/or advisory board member and/or consultant and/or speaker for any company.

J. A-D. has participated as a clinical investigator and/or advisory board member and/or consultant and/or speaker for Danone/ Nutricia, Astra Zeneca and Prospectos.

A.Z. has not participated as a clinical investigator and/or advisory board member and/or consultant and/or speaker for any company.

\section{References}

[1] Thomson M, Tringali A, Dumonceau JM et al. Pediatric gastrointestinal endoscopy: European Society for Paediatric Gastroenterology Hepatology and Nutrition (ESPGHAN) and European Society of Gastrointestinal Endoscopy (ESGE) Guidelines. J Pediatr Gastroenterol Nutr 2016; 00: 00-00 PAP

[2] Heuschkel RB, Gottrand F, Devarajan K et al. ESPGHAN position paper on management of percutaneous endoscopic gastrostomy in children and adolescents. J Pediatr Gastroenterol Nutr 2015; 60: 131-141

[3] Koletzko S, Jones NL, Goodman KJ et al. Evidence-based guidelines from ESPGHAN and NASPGHAN for Helicobacter pylori infection in children. J Pediatr Gastroenterol Nutr 2011; 53: 230-243

[4] Turner D, Levine A, Escher JC et al. Management of pediatric ulcerative colitis: joint ECCO and ESPGHAN evidence-based consensus guidelines. J Pediatr Gastroenterol Nutr 2012; 55: 340-361

[5] Guyatt GH, Oxman AD, Vist GE et al. GRADE: an emerging consensus on rating quality of evidence and strength of recommendations. BM] 2008; 336: $924-926$

[6] Dumonceau JM, Hassan C, Riphaus A et al. European Society of Gastrointestinal Endoscopy (ESGE) Guideline Development Policy. Endoscopy 2012; 44: 626-629 